\title{
Analysis of the Impact of Local Government Competition on Green Total Factor Productivity From the Perspective of Factor Market Distortion- Based on the Three-Stage DEA model
}

Juan Tang

Xinjiang University

Fangming Qin ( $\sim$ qinfmxjedu@163.com )

Xinjiang University

\section{Research Article}

Keywords: Three-stage DEA model, Local government competition, Green total factor productivity, Economic growth, Factor market distortion

Posted Date: March 22nd, 2021

DOl: https://doi.org/10.21203/rs.3.rs-272778/v1

License: (c) (i) This work is licensed under a Creative Commons Attribution 4.0 International License.

Read Full License 


\section{Analysis of the impact of local government competition on green total factor productivity from the perspective of factor market distortion --Based on the Three-stage DEA model Juan Tang a, , Fangming Qin ${ }^{\text {a, * }}$ \\ a School of Economics and Management, Xinjiang University, Urumqi 830047, China}

Abstract: From the perspective of factor market distortion, this paper explores the effect and internal mechanism of local government competition on green total factor productivity (GTFP). A threestage DEA model was applied to measure the GTFP of 30 provinces from 2008 to 2017. Furthermore, the article analyses local government competition and factor market distortions influence on GTFP using the Spatial SDM model and mediation effect model. The statistical results reveal that the spatial correlation of GTFP is significantly present across Chinese different provinces. The growth of GTFP will be significantly inhibited by local government competition. Local government competition can indirectly restrict the improvement of GTFP through factor market distortion. Regional heterogeneity indicates that, in the eastern and central regions, local government competition does not significantly inhibit the growth of GTFP. Moreover, local government competition failed to restrain the improvement of GTFP through factor market distortion. However, in the western region, local government competition not only inhibited the growth of GTFP, but also inhibited the growth of GTFP by causing factor market distortion.

Keywords: Three-stage DEA model; Local government competition; Green total factor productivity; Economic growth; Factor market distortion

\section{*: Corresponding author.}

E-mail addresses: tangjuanxjedu@163.com (Juan Tang); qinfmxjedu@163.com (Fangming

Qin). 


\section{Introduction}

The Chinese government has achieved a miracle of rapid economic growth for many years. Scholars generally believe that local government competition lays the institutional foundation for China's reform and opening up, which is one of the important reasons for China's excellent economic achievements (Ouyang et al.,2019; Wu et al.,2020). Since the implementation of the tax-sharing reform in 1994, the division of powers and responsibilities of the government has not only formed a vertical game between the central government and local governments, but also caused horizontal competition among local governments (Boyne, 1996; Hong et al.,2020). The central government maintains the right of political concentration and rewards and punishments for officials and creates a situation in which local officials at all levels compete for growth and promotion (Edmiston and Turnbull,2003). Stimulated by the promotion tournament, local officials are committed to economic development and attracting foreign direct investment to promote economic development and social progress (Hawkins, 2010; Yang et al.,2020). However, this competition mode not only results in the unreasonable allocation of local economic resources but also causes serious eco-environmental problems (Hao et al.,2020; Wu et al.,2020; Yang et al.,2020). Besides, to maximize economic benefits and local protectionism, local government officials blindly allocate resources and factors of production to promote short-term rapid economic growth (Levinson, 2003; Markusen et al.,1995). As a result, the factor market-oriented lags behind the product market-oriented. The price of factors is generally undervalued, and the free flow of factors is also hindered, resulting in factor market distortion (Oates and Schwab, 1988; Zhang et al.,2020).

With the new development concept as the backdrop of the times, the Chinese government has pointed out that it is necessary to promote the reform of economic quality, efficiency, and dynamism, so as to improve the total factor productivity (Sun et al.,2020; Zhao et al.,2020). However, guided by the conviction that lucid waters and lush mountains are invaluable assets, local governments only consider the efficiency of economic development is still insufficient (Sun et al.,2019; Shi et al.,2020) . Economic development is compatible with the protection of the environment. How to coordinate the relationship between economic development and ecological environment, and at the lowest cost of resources and environment in exchange for sustained economic growth is the primary goal of local government competition (Chen et al., 2020). Green total factor productivity (GTFP) is the crucial content of the coordination among economic development, resource conservation, and environmental governance. GTFP improvement can not only promote local economic development but also effectively solve environmental pollution problems. Therefore, this paper uses GTFP as an index to measure the coordination between economic growth and eco-environmental protection. From the perspective of factor market distortion, this study analyzes local government competition's influence on GTFP. It is expected to provide some evidence for optimizing government management system, reasonably guiding local government behavior, alleviating the contradiction between environmental protection and economic development, and promoting the green transformation of economic development mode.

\section{Literature review}

\subsection{Local government competition and green total factor productivity}

Since the 1950s, a kind of organizational structure of political centralization and economic decentralization have been formed between the central and local governments in China (Lin and Liu, 2000; Zhang et al.,2020). Especially in the aspect of environmental public service, political 
centralization affects the preference of local government (Hong et al.,2020) The economic decentralization endows the local government with certain financial autonomy, which leads to local government competition (Oates, 1993; Baskaran and Feld,2013). Under this governance model with Chinese characteristics of political centralization and economic decentralization, Local government preferences dominate the scale of local government competition(Liu et al.,2019) The preference and importance of local governments for eco-environmental protection are crucial to the improvement of China's GTFP (Song et al.,2018).

The research on local government competition and GTFP is mainly divided into two different viewpoints. One kind of viewpoint out that local government competition enables local governments to choose to formulate corresponding environmental governance policies on the basis of the specific conditions of their respective jurisdictions (Song et al.,2020). Environmental pollution has been controlled, the environment and economy have achieved a win-win situation (Ogawa and Wildasin, 2009). For example, Zhou (2007) confirms that there is scale competition among local governments, and they promote economic development goals through games, strategic interaction, and spillover effects, which have an important impact on the growth of GTFP. Haufler and Maier (2019) pointed out that the competition focus of local governments has shifted to competition for quality improvement, which will help to promote the implementation of regional environmental protection and emission reduction projects(Kivyiro and Arminen.,2014). Deng et al. (2019) explained that local government competition promotes economic development through the effect of attracting foreign investment. Regional technological innovation is nurtured by economic development, which plays a positive role in GTFP (Deng et al.,2019). Other scholars follow this view that since the Chinese fiscal and taxation system, financial control was devolved to the higher authorities, the management of affairs was devolved to the subordinate, and local governments have become independent interest groups (Zhang et al.,2020). The characteristics of political centralization and the promotion mechanism of officials based on performance assessment make local governments attach importance to public affairs such as economic growth, infrastructure construction, and neglect of environmental protection (Song et al.,2018; Wu et al.,2020; Hao et al.,2020 ). Besides, under the situation where the GDP growth rate is the crucial performance assessment for officials' behavior, local governments usually absorb foreign capital, labor, and other mobile factors at all costs. The above actions will not only lower the regulatory standards of eco-environmental pollution, but also sacrifice the environment for economic growth, resulting in "bottom-to-bottom competition"(Porter,1999; Revelli and Tovmo, 2007; Kuai et al.,2019). Finally, in the short term, as environmental governance can not be rewarded, local governments in this region fall into the "prisoner's dilemma" in order to prevent the surrounding " free rider"( Li et al.,2019). As a result, the neighboring local governments have no motivation to prevent and control eco-environmental pollution, causing damage to GTFP (Li et al.,2016).

\subsection{The impact of factor market distortions on green total factor productivity}

The analytical framework for factor market distortions in China was pioneered by Hsieh et al. (2009). Based on the above framework, different scholars have studied factor market distortions influence on GTFP in China (Lin and Chen,2018). Most scholars have found that factor market distortion is a crucial role in leading to the decrease of GTFP. Lin and Chen (2018) point out that due to the marketization process is not perfect in the early stage of Chinese economic development, the allocation of factor resources mainly depends on the administrative means of the 
government(Lin, 2012). However, the actual effect of the government's allocation of factor resources is often unsatisfactory (Yang et al.,2018). Government officials, as the makers and implementers of interventionist policies, have the dual attributes of both political man and economic man. The behavior and decision-making of government officials are inevitably influenced by the motivation of maximizing personal interests, which distorts the factor market and ultimately affects GTFP (Huang and Tao, 2010). To achieve the specific economic growth goal, the government usually intervenes with the factor price, which makes it difficult for the factor price to truly reflect the scarcity degree of the factor (Yang et al.,2021). However, the "rational decisions" made by enterprises and manufacturers based on distorted factor prices will lead to the accumulation of inherent contradictions in economic development (Kui-za, 2015).

In addition, Deng et al. (2021) found that capital price distortions will create false incentives for investment, exacerbating the worsening effect of investment on overcapacity. Dierkes et al.(2020) pointed out that government intervention in the factor market will distort the investment decisions of enterprises and induce enterprises to blindly enter the industry of overcapacity, resulting in a large number of repetitive investments and waste of factor resources. Shi et al. (2017) believe that arbitrage caused by factor price distortion leads to the flow of a large number of factor resources to extensive production projects with quick results and low uncertainty, which makes economic growth extension expansion-driven by factor resources. Gao(2019) found that the traditional way of resource allocation must be changed, that is, from "government leading + market plays a basic role" to "service-oriented government + market plays a decisive role", to meet the inherent requirements resource allocation. However, the factor mismatch formed under the traditional resource allocation model is not good for the sustainable growth of GTFP (Lin and Chen, 2018).

To sum up, many scholars make an in-depth study on local government competition, factor market distortion, and GTFP from different levels, which lays a solid foundation for the theoretical framework analysis of this paper. However, few scholars have addressed the issue of factor market distortions in their studies of local government behavior and GTFP. And the relationship among local government competition, factor market distortion, as well as GTFP, has not been brought into the unified framework for analysis. For example, at present, most scholars study the economic and environmental benefits of economic growth or local government behavior based on the factor market distortion approach (Chaudhuri, 2005; Liu and Qiu,2020; Zhang et al.,2020). Therefore, this paper intends to start from the institutional level and take factor market distortion as the entry point to verify the internal mechanism and influence of factor market distortion and local government competition on GTFP.

This article contributed as follows. First of all, the three-stage DEA model is applied to measure the green total factor productivity, which can effectively eliminate the errors caused by environmental factors and statistical noise. It provides a new perspective for further analysis of GTFP. Secondly, the spatial SDM model and the mediation effect model are used to empirically test both factor market distortion and local government competition influence on GTFP, which provide some empirical basis for the implementation of green development strategy in the future. Third, different from the previous measurement methods of factor market distortion, the benchmarking analysis method is used to measure factor market distortion, which makes up for the deficiency of the research related to factor market distortion. Finally, the offsetting or enhancement effects of local government competition and factor market distortion on GTFP under different regional characteristics are analyzed from a regional perspective. It broadens the current research field and 
provides a decision-making reference for the implementation of different policy tools.

\section{Methods}

\subsection{Measurement of Green Total Factor Productivity}

\subsubsection{Three-stage DEA model}

The relative efficiency of a decision-making unit (DMU) is affected by multiple factors such as management inefficiency, environmental factors, and statistical noise ( $\mathrm{Li}$ and Lin, 2016). The traditional DEA model does not take the above factors into full consideration. Instead, environmental factors and statistical noise are all attributed to management inefficiency, which will cover up the real efficiency value only affected by management factors and the analysis of relative efficiency. Therefore, Following Fried (2002), a three-stage DEA model was employed to effectively remove environmental factors and statistical noise influence on relative efficiency values through stochastic frontier analysis. The specific measurement process is as follows.

The first stage: Undesirable outputs model.

The Undesirable model, which contains both desired and undesired outputs, can effectively reduce the effects of raw data modification and subjective factors(Fuentes et al.,2016). This paper sets $\operatorname{DUM}\left(X_{0}, Y_{0}\right) \quad X_{0}$ as input and $Y_{0}$ as output. $Y_{0}$ contains the desirable output $\left(Y^{g}\right)$ and the undesirable output $\left(Y^{b}\right)$, which are named $\operatorname{DUM}\left(X_{0}, Y^{g}, Y^{b}\right)$. The production possibility set is set to $P=\left\{\left(x, y^{g}, y^{b}\right) \mid x \geq X, y^{g} \leq Y^{g}, y^{b} \geq Y^{b}, L \leq e \lambda \leq U, \lambda \geq 0\right\}$. The model form is shown in Equation(1):

$$
\rho^{*}=\min \frac{1-\frac{1}{m} \sum_{i=1}^{m} \frac{S_{i 0}^{-}}{X_{i 0}}}{1+\frac{1}{S}\left(\sum_{r=1}^{s_{1}} \frac{S_{r}^{g}}{y_{r 0}^{g}}+\sum_{r=1}^{s_{2}} \frac{S_{r}^{b}}{y_{r 0}^{b}}\right)}
$$

.6

(1)

(1)




$$
S_{m j}=f^{m}\left(Z_{j} ; \beta^{m}\right)+v_{m j}+u_{m j}, m=1,2, \cdots M, j=1,2, \cdots N
$$

Where, $S_{m j}=x_{m j}+X_{m} \lambda$ represents the redundancy value of the Mth input variable of the Jth DMU in the first stage. $Z_{j}$ represents the unbalanced factor of regional development in the Jth DMU. $\beta^{m}$ is the parameter estimate value of the variable of regional development imbalance. $u_{m j}$ represents random interference, which ensures the inefficiency of management.

Then, the SFA model is applied to adjust all decision-making units to both the same random interference state and the same external environment, to obtain the pure efficiency value (PE) excluding the influence of regional development imbalance(Chen et al.,2016). The decision-making units with better external non-operating factors are selected to increase the adjustment amount of their input, and the adjustment of the input amount of each decision-making unit are as follows:

$$
x_{m j}^{A}=x_{m j}+\left[\max \left\{f^{m}\left(Z_{j} ; \hat{\beta}^{m}\right)\right\}-f^{m}\left(Z_{j} ; \hat{\beta}^{m}\right)\right]+\left[\max \left\{\hat{v}_{m j}\right\}-\hat{v}_{m j}\right], 1,2, \cdots M, j=1,2, \cdots N
$$

Among them, $x_{m j}^{A}$ represents the adjusted value of the $m_{t h}$ input variable of the $j_{t h} D M U$, which means that the random interference of all decision-making units is adjusted to the same state. To get $\hat{v}_{m j}$ value, referring to Jondrow et al.(1982), we set up the following equation:

$$
\begin{gathered}
\hat{E}\left[v_{m j} \mid v_{m j}+u_{m j}\right]=S_{m j}-f^{m}\left(Z_{j} ; \hat{\beta}^{m}\right)-\hat{E}\left[u_{m j} \mid v_{m j}+u_{m j}\right] \\
E\left[u_{m j} \mid v_{m j}+u_{m j}\right]=\mu_{*}+\sigma_{*} \frac{f\left(-\mu_{*} / \sigma_{*}\right)}{1-F\left(-\mu_{*} / \sigma_{*}\right)}
\end{gathered}
$$

Where, $\sigma^{2}=\sigma_{u}^{2}+\sigma_{v}^{2}, \mu_{*}=-\sigma^{2} \varepsilon /_{\sigma^{2}}, \sigma_{*}^{2}=\sigma_{u}^{2} \sigma_{v}^{2} /_{\sigma^{2}}, \varepsilon=S_{m j}-f^{m}\left(Z_{j} ; \hat{\beta}^{m}\right)$.

The three-stage.

Once again, the relative efficiency value was calculated by the Undesirable outputs model. Through the regression results of the second stage, the input of each decision-making unit is adjusted to keep the output unchanged. Then, the relative efficiency value of eliminating environmental factors and statistical noise were obtained by using the Undesirable outputs model, and the efficiency value is

\begin{tabular}{|c|c|c|c|}
\hline Indicator types & Index composition & Definition & References \\
\hline \multirow{3}{*}{ Input indicator } & Capital stock & $\begin{array}{l}\text { Total investment in } \\
\text { fixed assets }\end{array}$ & Wu et al. (2020) \\
\hline & Labor & $\begin{array}{l}\text { Number of employed } \\
\text { persons in urban units }\end{array}$ & Hao et al. (2020) \\
\hline & Energy consumption & $\begin{array}{l}\text { Coal, natural gas, } \\
\text { electricity, oil, and } \\
\text { heat, etc. (10,000 tons } \\
\text { of standard coal) }\end{array}$ & $\begin{array}{c}\text { Hao et al.(2019); Shi } \\
\text { et al.(2020) }\end{array}$ \\
\hline $\begin{array}{c}\text { desirable output } \\
\text { indicator }\end{array}$ & GDP & $\begin{array}{c}\text { Total GDP of each } \\
\text { province }\end{array}$ & Li et al.(2020) \\
\hline $\begin{array}{l}\text { Undesired output } \\
\text { indicator }\end{array}$ & $\begin{array}{l}\text { Environmental } \\
\text { pollution }\end{array}$ & $\begin{array}{c}\text { Industrial sulfur } \\
\text { dioxide emissions, } \\
\text { total industrial } \\
\text { wastewater emissions, }\end{array}$ & Zhu et al.(2019) \\
\hline
\end{tabular}
analyzed.

3.1.2. Calculate the index evaluation system of green total factor productivity

Table1 Calculate the index evaluation system of green total factor productivity 


\begin{tabular}{|c|c|c|c|}
\hline & & $\begin{array}{l}\text { industrial nitrogen } \\
\text { oxide emissions, } \\
\text { industrial smoke } \\
\text { (powder) dust } \\
\text { emissions, total } \\
\text { industrial chemical } \\
\text { oxygen demand } \\
\text { emissions and total } \\
\text { industrial ammonia } \\
\text { nitrogen emissions }\end{array}$ & \\
\hline \multirow{4}{*}{ Envionment indicator } & Urbanization & $\begin{array}{l}\text { The proportion of } \\
\text { urban resident } \\
\text { population to the total } \\
\text { population at the end } \\
\text { of the year }\end{array}$ & Hao et al.(2019) \\
\hline & Industrial structure & $\begin{array}{l}\text { The ratio of the added } \\
\text { value of the tertiary } \\
\text { industry to that of the } \\
\text { secondary industry }\end{array}$ & Yang et al.(2020) \\
\hline & Financial development & $\begin{array}{l}\text { Deposits and loans of } \\
\text { financial institutions } \\
\text { per unit of GDP }\end{array}$ & Wang et al.(2020) \\
\hline & Openness & $\begin{array}{l}\text { Imports and exports } \\
\text { per unit of GDP }\end{array}$ & Zhang et al.(2020) \\
\hline
\end{tabular}

\subsection{Calculation results of green total factor productivity}

\subsubsection{Stage 1:}

This paper analyzes the evaluation results of GTFP in three stages. Limited by space, this paper only shows the results of GTFP measurement in the third stage. This paper analyzes the GTFP evaluation results in three stages. We only present the third phase of GTFP measurement by space constraints. Table 2 shows that ignoring the interference of environmental factors and random errors, the mean value of GTFP is 0.595 , the mean value of pure technical efficiency (PE) is 0.670 , and the mean value of scale efficiency (SE) is 0.900 . We find that pure technical efficiency (PE) pulls down the green TFP overall. From the data of each province, the GTFP of Guangdong,Shanghai, Beijing, and Tianjin are relatively high, which is at the forefront of production efficiency. However, the GTFP of Shanxi, Shaanxi, Gansu, Ningxia, Xinjiang, and other 12 regions is less than 0.500.

Table 2 Average efficiency of the first stage

\begin{tabular}{|l|l|l|l|}
\hline DMU & $1-\mathrm{TE}$ & $1-\mathrm{PTE}$ & $1-\mathrm{SE}$ \\
\hline Beijing & 1.000 & 1.000 & 1.000 \\
\hline Tianjin & 1.000 & 1.000 & 1.000 \\
\hline Hebei & 0.498 & 0.548 & 0.910 \\
\hline Shanxi & 0.379 & 0.401 & 0.945 \\
\hline Inner Mongolia & 0.904 & 0.908 & 0.996 \\
\hline Liaoning & 0.468 & 0.492 & 0.950 \\
\hline
\end{tabular}




\begin{tabular}{|l|l|l|l|}
\hline Jilin & 0.499 & 0.527 & 0.947 \\
\hline Heilongiiang & 0.522 & 0.537 & 0.973 \\
\hline Shanghai & 1.000 & 1.000 & 1.000 \\
\hline Jiangsu & 0.853 & 1.000 & 0.853 \\
\hline Zhejiang & 0.664 & 0.694 & 0.956 \\
\hline Anhui & 0.498 & 0.516 & 0.965 \\
\hline Fujian & 0.636 & 0.649 & 0.979 \\
\hline Jiangxi & 0.516 & 0.537 & 0.960 \\
\hline Shandong & 0.769 & 0.893 & 0.861 \\
\hline Henan & 0.510 & 0.543 & 0.939 \\
\hline Hubei & 0.594 & 0.611 & 0.972 \\
\hline Hunan & 0.583 & 0.608 & 0.959 \\
\hline Guangdong & 1.000 & 1.000 & 1.000 \\
\hline Guangxi & 0.521 & 0.546 & 0.955 \\
\hline Hainan & 0.667 & 1.000 & 0.667 \\
\hline Chongqing & 0.529 & 0.555 & 0.954 \\
\hline Sichuan & 0.544 & 0.566 & 0.962 \\
\hline Guizhou & 0.403 & 0.470 & 0.858 \\
\hline Yunnan & 0.428 & 0.455 & 0.940 \\
\hline Shanxi & 0.477 & 0.493 & 0.969 \\
\hline Gansu & 0.375 & 0.444 & 0.845 \\
\hline Qinghai & 0.363 & 1.000 & 0.363 \\
\hline Ningxia & 0.317 & 0.708 & 0.448 \\
\hline Xinjiang & 0.342 & 0.389 & 0.881 \\
\hline Mean & 0.595 & 0.670 & 0.900 \\
\hline & & & \\
\hline
\end{tabular}

\subsubsection{Stage 2:}

In this stage, the SFA regression model was constructed with the employed people in urban units, the capital stock and the slack amount of energy consumption as the dependent variables, and the four external environmental variables such as financial development, urbanization, industrial structure, and openness as the independent variables (see Table 3). The LR unilateral implies that the SFA model has strong applicability. $\delta^{2}$ and $\gamma$ values are significantly positive at $1 \%$, showing that environmental factors were more significant than random errors. Most of the coefficients of the environmental variables on input slack pass the significance test. Specifically, financial development significantly reduces capital input slack and it significantly contributes to energy input slack. However, there is no correlation between financial development and labor input slack. These results indicate that regions with higher financial development can promote the efficient use of assets, but it will increase energy consumption. Urbanization significantly contributes to labor input slack, which significantly inhibits slack concerning capital and energy inputs. The coefficient of industrial structure variable on personnel and asset investment slack is not significant, while the influence coefficient on energy slack is significantly negative. The possible reason is that China's industrial focus is gradually shifting from the secondary industry to the tertiary industry. Laborintensive industries were gradually replaced by knowledge-intensive industries, thus significantly reducing energy consumption. The coefficients of openness on labor, capital, and energy slack are 
significantly negative, indicating that increasing the level of openness has a positive impact on the growth of GTFP.

Table 3 Regression results of SFA model

\begin{tabular}{cccc}
\hline Variables & Labor input slack & Capital stock input slack & $\begin{array}{c}\text { Energy consumption } \\
\text { input slack }\end{array}$ \\
\hline Constant & $-105.96688^{* * *}$ & $10583.464^{* * *}$ & $2183.302^{* * *}$ \\
Financial & $(2.755)$ & $(8.578)$ & $(6.881)$ \\
development & 10.60796 & $-2605.0721^{*}$ & $738.47526^{*}$ \\
& $(0.599)$ & $(-1.703)$ & $(1.650)$ \\
Urbanization & $223.47571^{* * *}$ & $-4277.0055^{* * *}$ & $-2461.4235^{* * *}$ \\
& $(3.099)$ & $(-2.744)$ & $(-5.287)$ \\
Industrial & -5.8465577 & -3035.736 & $-936.68161^{*}$ \\
structure & $(-0.309)$ & $(-1.545)$ & $(-1.931)$ \\
& $-109.9559^{* * *}$ & $-8291.5417^{* * *}$ & $-1555.8682^{* * *}$ \\
Openness & $(-4.217)$ & $(-9.183)$ & $(-2.913)$ \\
& $16868.756^{* * *}$ & $406287810^{* * *}$ & $26879069^{* * *}$ \\
$\sigma^{2}$ & $(13434.172)$ & $(406286700.000)$ & $(26828632.000)$ \\
$\gamma$ & $0.75429586^{* * *}$ & $0.90856883^{* * *}$ & $0.92007743^{* * *}$ \\
$\gamma$ & $(34.985)$ & $(117.598)$ & $(132.955)$ \\
Log function & 1719.4332 & -3088.6941 & -2664.1034 \\
value & $148.47015^{* * *}$ & $360.97897^{* * *}$ & $395.44607^{* * *}$ \\
\hline LR unilateral test & &
\end{tabular}

273

The parentheses represent $\mathrm{Z}$ statistics. $* * *$ is significant at $1 \%$;* is significant at $5 \%$; ${ }^{*}$ is significant at $10 \%$.

\subsubsection{Stage 3:}

Table 3 shows that the average value of GTFP after adjustment is 0.611 , which is higher than the efficiency value before adjustment, but still at a low level. The fact is that even if the input is reduced by $38.9 \%$, the original output level can be achieved by enhancing resource utilization efficiency and improving operation and management. The average value of the adjusted PTE is 0.786 , which has a small gap with the frontier of efficiency, but it forms a great contrast with the value before adjustment. The above results show that the Chinese government has made certain achievements in attaching great importance to technological innovation in recent years. The average value of $S E$ after adjustment is 0.773 , which is lower than that before adjustment. This may be caused by the fact that the innovator pays too much attention to the application of technology while neglecting the moderate scale production in the daily operation. Compared with the first stage, the average value of TE and PTE increased by 0.016 and 0.116 respectively, and the average value of $S E$ decreased by 0.127 . The adjusted efficiency results show that the low GTFP in China is mainly caused by the low scale efficiency level. Improving scale efficiency is an important task for local governments. Besides, Shanghai, Jiangsu, Beijing, and Guangdong are at the forefront of the adjusted production efficiency. Compared with the pre-adjustment, the number of areas where the GTFP is less than 0.500 has dropped to 8 . The results show that environmental variables have a 
great impact on GTFP in different regions.

Table 4 The average efficiency of the third stage

\begin{tabular}{|l|l|l|l|}
\hline DMU & 3 -TE & 3 -PTE & $3-$ SE \\
\hline Beijing & 1.000 & 1.000 & 1.000 \\
\hline Tianjin & 0.906 & 1.000 & 0.906 \\
\hline Hebei & 0.621 & 0.672 & 0.925 \\
\hline Shanxi & 0.416 & 0.558 & 0.746 \\
\hline Inner Mongolia & 0.858 & 0.968 & 0.886 \\
\hline Liaoning & 0.563 & 0.614 & 0.916 \\
\hline Jilin & 0.522 & 0.697 & 0.748 \\
\hline Heilongjiang & 0.568 & 0.696 & 0.815 \\
\hline Shanghai & 1.000 & 1.000 & 1.000 \\
\hline Jiangsu & 1.000 & 1.000 & 1.000 \\
\hline Zhejiang & 0.755 & 0.795 & 0.950 \\
\hline Anhui & 0.553 & 0.660 & 0.838 \\
\hline Fujian & 0.677 & 0.795 & 0.852 \\
\hline Jiangxi & 0.509 & 0.743 & 0.685 \\
\hline Shandong & 0.915 & 0.921 & 0.994 \\
\hline Henan & 0.604 & 0.655 & 0.921 \\
\hline Hubei & 0.661 & 0.732 & 0.902 \\
\hline Hunan & 0.725 & 0.839 & 0.865 \\
\hline Guangdong & 1.000 & 1.000 & 1.000 \\
\hline Guangxi & 0.520 & 0.693 & 0.751 \\
\hline Hainan & 0.379 & 1.000 & 0.379 \\
\hline Chongqing & 0.545 & 0.726 & 0.750 \\
\hline Sichuan & 0.643 & 0.704 & 0.914 \\
\hline Guizhou & 0.387 & 0.797 & 0.485 \\
\hline Yunnan & 0.440 & 0.643 & 0.684 \\
\hline Shanxi & 0.530 & 0.665 & 0.796 \\
\hline Gansu & 0.335 & 0.678 & 0.494 \\
\hline Qinghai & 0.182 & 1.000 & 0.182 \\
\hline Ningxia & 0.181 & 0.771 & 0.235 \\
\hline Xinjiang & 0.333 & 0.572 & 0.581 \\
\hline Mean & 0.611 & & \\
\hline
\end{tabular}

\subsection{Economic strategy}

\subsubsection{Spatial Durbin Model}

Spatial correlation may be derived from the explanatory variable itself, the explanatory variable, and the error term(Lesage, 2009). Therefore, the spatial Durbin model, which can capture regional spatial heterogeneity and competition characteristics, is applied to analyse the research content of this paper. The spatial Durbin model is constructed as follows: 
government competition. $\alpha$ represents the estimated coefficient. $X$ are a series of control variables, such as human capital (hum), per capita road area (roa), marketization level (mar), intellectual property protection level (pro). $\rho$ is the spatial spillover coefficient of gtfp. $W$ is $n \times n$ order spatial weight matrix. $\mu$ represents an individual fixed. $v$ represents a time fixed. The random disturbance term is $\varepsilon$.

The mediation effect model uses the third variable to explore the internal mechanism of independent variables affecting dependent variables. Following Baron and Kenny (1986), the regression models are constructed. Considering the heteroscedasticity of the model, the least square estimation method of robust standard error (2SLS) is used to estimate the mediation effect. The specific models are as follows:

$$
\begin{aligned}
& g t f p_{i t}=\beta_{0}+\beta_{1} l g c_{i t}+\sum_{k=2}^{5} \beta_{k} X_{i t}+\varepsilon_{i t} \\
& \text { fmd }_{i t}=\delta_{0}+\delta_{1} l g c_{i t}+\sum_{k=2}^{5} \delta_{k} X_{i t}+\varepsilon_{i t} \\
& g t f p_{i t}=\emptyset_{0}+\emptyset_{1} l g c_{i t}+\emptyset_{2} f m d_{i t}+\sum_{k=3}^{6} \emptyset_{k} X_{i t}+\varepsilon_{i t}
\end{aligned}
$$

Where, fmd is the mediation variable, which represents the factor market distortion index. The mediation effect model is jointly constructed by Eqs. (2)-(4). If $\delta_{1}$ and $\emptyset_{2}$ in Eq (3) and Eq. (4) are significant, it implies that the core explanatory variable will significantly influence the dependent variable through the mediation variable, and its mediation effect is $\delta_{1} \times \emptyset_{2}$. Following Iacobucci $(2012){ }^{1}$ the test settings are as follows:

$$
Z_{\text {mid }}=\frac{Z_{\delta} \times z_{\varnothing}}{\sqrt{z_{\delta}^{2}+z_{\varnothing}^{2}}}
$$

$Z_{\text {mid }}$ the test is to measure the significance of the mediation effect by using Eq. (5) when the variable is continuous. $\delta$ in the formula represents the influence coefficient of com on $\mathrm{fmd} . \emptyset$ represents the influence coefficient of $f m d$ on gtfp. $Z_{\delta}$ and $Z_{\emptyset}$ represent the $\mathrm{T}$ value of coefficient $\delta$ and coefficient $\varnothing$, respectively.

\subsubsection{Matrix construction and spatial correlation test}

The spatial weight matrix is generated using the geographical locations of provinces, municipalities, and autonomous regions, denoted as $W$. Because $g t f p$ is greatly influenced by the mutual influence between geographical regions, this paper calculates the geographical distance among regional centers according to the longitude and latitude of the administrative centers of each province and city, and only takes the reciprocal treatment of the difference between longitude and latitude. $W_{i j}$ is expressed as follows:

$$
W_{i j}\left\{\begin{array}{c}
\frac{1}{d_{i j}}, i \neq j \\
0, i=j
\end{array}\right.
$$

Among them, The geographical distance from region $i$ to region $j$ is represented using $d$.

(2) Spatial correlation test. This paper will use the global Moran index(I) to examine the global autocorrelation of variables and data in 30 provinces of China. The expression of the formula is as follows:

$$
I_{i}=\frac{n \sum_{j=1}^{n} W_{i j}\left(\alpha_{i}-\bar{\alpha}\right)\left(\alpha_{j}-\bar{\alpha}\right)}{\sum_{i=1}^{n}\left(\alpha_{i}-\bar{\alpha}\right)}
$$

\footnotetext{
${ }^{1}$ The advantage of this approach that the likelihood of making the first type of error is minimal, which is usually lower than the significant level, thus ensuring the validity of the results.
} 
Among them, $I$ represents the global Moran's I $(-1<I<I) . n$ refer to individuals in the sample $(\mathrm{n}=30)$. W refers to the spatial weight matrix; $\alpha_{i}$ is the GTFP of the $i$ province. $\bar{\alpha}$ is the arithmetic average of $n$. If $\mathrm{I}>0$, it shows that each region is positive spatial autocorrelation, and if $\mathrm{I}<0$, it is a negative correlation.

\subsubsection{Variables selection}

Dependent variable.

Green total factor productivity $(g t f p)$. Green total factor productivity $(g t f p)$ is characterized by the efficiency value of the third stage measured in the previous article, and the specific calculation process will not be described in detail.

Core explanatory variable.

Local government competition $(\lg c)$. In the early stages of economic development, China's economic foundation is weak and the technology level is also backward. In order to promote economic growth, local governments construct a large number of labor-and resource-intensive industries by introducing foreign capital. A large number of low value-added industries have caused ecological damage and environmental pollution. Foreign investment has been used as a major target for local governments competing for factor flows, with indelible effects on the ecological environment and economic growth. The more foreign investment in a province, the stronger the competitiveness of the region. Following Zhang et al. (2020), the ratio of foreign direct investment to GDP is employed to characterize local government competition.

Mediation variable.

Factor market distortion ( $f m d$ ).Referring to Zhang et al.(2020). Factor market distortions $(f m d)$ are measured as the relative difference between the degree of factor market development in a given region and the degree of factor market development in a benchmark(Lin and Chen,2018). The advantage of this indicator is that it not only reflects the dynamic characteristics of the degree of factor market distortion in a particular region, but also the relative difference between regions. The calculation formula is set as follows

$$
f m d_{i t}=\frac{\max S E_{i t}-S E_{i t}}{\max S E_{i t}}
$$

Where, $\max S E_{i t}$ represents factor market development maximum degree. $S E_{i t}$ represents factor market development degree. $f m d_{i t}$ represents the degree of distortion in factor markets. Control variables.

While the environmental variables affecting GTFP have been eliminated, the following control variables are selected. Specifically, the per capita number of years of education in each province and city is applied to characterize the human capital(hum). The per capita road area of each city is used to measure the level of traffic infrastructure( $r o a)$. Marketization level(mar) and intellectual property protection (pro) are respectively measured by the proportion of non-state-owned enterprise employees in employment and the ratio of provincial and municipal technology market transaction volume to GDP.

Data source. The calculation method of factor market distortion changed after 2008 in China Marketization Progress Index Report, so this paper selected China's provincial panel data from 2008 to 2017 as the research object. The relevant data are from China Marketization Process Index Report, EPS database, and China Environment Statistics Yearbook. The data definitions are shown in Table 5. Besides, the variance inflation factor (VIF ) shows that there is no multicollinearity problem of each variable. 
Table 5 Data definitions

\begin{tabular}{ccccccc}
\hline Variables & $\mathrm{N}$ & MEAN & SD & MIN & MAX & VIF \\
\hline gtfp & 300 & 0.611 & 0.251 & 0.148 & 1 & $/$ \\
hum & 300 & 8.915 & 0.945 & 6.764 & 12.50 & 3.61 \\
roa & 300 & 4.624 & 1.983 & 0.909 & 10.51 & 1.74 \\
mar & 300 & 0.715 & 0.107 & 0.440 & 0.899 & 2.03 \\
lgc & 300 & 0.233 & 0.0985 & 0.0874 & 0.627 & 1.68 \\
pro & 300 & 0.0111 & 0.0242 & 0.000186 & 0.160 & 2.28 \\
fmd & 300 & 0.652 & 0.162 & 0 & 0.977 & 2.84 \\
\hline
\end{tabular}

386

387

388

389

390

391

392

393

394

395

396

397

398

399

400

401

402

403

404

405

406

\section{Results and discussions}

\subsection{Applicability test of the spatial econometric model}

Table 6 shows that, as a whole, the Moran's I is significantly positive from 2008 to 2017. The spatial distribution of GTFP is significantly spatially positively correlated. However, the Moran's I index value in 2008 did not pass the significance test. One possible reason is that due to the impact of the subprime mortgage crisis in the United States, the spatial autocorrelation of inter-provincial GTFP in 2008 is not significant.

Table 6 The global Moran's I index

\begin{tabular}{lccccc}
\hline Variables & 2008 & 2009 & 2010 & 2011 & 2012 \\
\hline Moran's I & 0.019 & $0.024^{*}$ & $0.028^{*}$ & $0.044^{* *}$ & $0.055^{* *}$ \\
& $(1.211)$ & $(1.342)$ & $(1.444)$ & $(1.792)$ & $(2.029)$ \\
\hline Variables & 2013 & 2014 & 2015 & 2016 & 2017 \\
\hline Moran's I & $0.049 * *$ & $0.049 * *$ & $0.043^{* *}$ & $0.025^{*}$ & $0.026^{*}$ \\
& $(1.896)$ & $(1.901)$ & $(1.747)$ & $(1.341)$ & $(1.369)$ \\
\hline
\end{tabular}

The parentheses represent $\mathrm{Z}$ statistics. ${ }^{* * *}$ is significant at $1 \%$; $*$ is significant at $5 \%$; ${ }^{*}$ is significant at $10 \%$.

Additionally, the applicability of the spatial econometric model is firstly determined by the LM error test and Robust LM error test. Subsequently, the specific spatial econometric model was further confirmed by the Hausman test, LR test, and Wald test (see Table7). Table 7 shows that LM error value and LM lag value are significant at least 5\% level. The test values of Robust LM error and Robust LM lag also are significant at the 5\% level. Hausman test showed that We should apply the spatial individual fixed Durbin effect model. LR and Wald test value implies that the spatial Durbin model with both space and time fixed is more suitable in this paper. Therefore, according to the test results of the above model, We use the spatial Durbin model with both space and time to carry on the empirical analysis of local government competition and GTFP.

Table 7 Results of model applicability test

\begin{tabular}{lcc}
\hline Test methods & Statistical value & P-value \\
\hline Moran's I & $2.534^{* *}$ & 0.011 \\
LM error & $4.515^{* *}$ & 0.034 \\
Robust LM error & $3.657^{*}$ & 0.056 \\
LM lag & $15.046^{* * *}$ & 0.000 \\
Robust LM lag & $14.188^{* * *}$ & 0.000 \\
LR for both or Ind & $61.90^{* * *}$ & 0.0000 \\
LR for both or Time & $439.97^{* * *}$ & 0.0000
\end{tabular}




$\begin{array}{lcc}\text { LR for SAR } & 25.15^{* * *} & 0.0001 \\ \text { LR for SEM } & 23.51^{* * *} & 0.0003 \\ \text { WALD for SAR } & 26.17^{* * *} & 0.0001 \\ \text { WALD for SEM } & 23.96^{* * *} & 0.0002 \\ \text { Hausman } & 12.48^{* *} & 0.0288\end{array}$

407

408

409

410

411

412

413

414

415

416

417

418

419

420

421

422

423

424

425

426

427

428

429

430

431

\subsection{Analysis of benchmark regression results}

For the convenience of comparison, the regression results of the OLS model, panel fixed effect model (FE), panel random effect (RE) model, and spatial Durbin model (SDM) are also presented (see Table 8). Column (1) - column (4) shows that local government competition inhibits GTFP (GTFP). Among them, the spatial Durbin model revealed that the regression coefficient of $l g c$ value is negatively significant at $10 \%$ when GTFP is used as the dependent variable, meaning local government competition is significantly reduce the GTFP. To catch up with the economy of other regions, local governments improve their political achievements at all costs(Hong et al.2020). First of all, in the case of promoting the assessment system with the ultimate goal of chasing GDP growth, some loose environmental policies are formulated by local governments to attract enterprises with high pollution, high emissions, and high energy consumption, which can usually quickly create economic benefits and protect jobs in a short period of time(Canavire-Bacarreza et al.,2019; Zheng et al.,2020). Secondly, the government's fiscal expenditure is biased toward in the direction of economic growth, crowding out the fiscal expenditure on environmental protection and energy conservation. Although local government actions speed up economic construction, they cause ecological damage and environmental pollution and finally inhibit GTFP(Pan et al., 2020). In addition, the coefficient of $\mathrm{W} * \lg c$ is positive but not significant, implying that the spillover effect of local government competition on GTFP in neighboring regions is not significant. $\rho$ value is significantly positive at $1 \%$. The results imply that GTFP in China has spatial autocorrelation characteristics during the sampling period. The growth of local GTFP will have a positive spillover effect on the neighboring areas, which means that although the local area will attract the human capital, capital, material resources, and other factors from the surrounding areas to gather locally, it will be helpful for the growth of GTFP in the neighboring areas with low competitiveness.

Table 8 Benchmark result regression

\begin{tabular}{ccccc}
\hline Variables & $\mathrm{Ols}$ & $\mathrm{Fe}$ & $\mathrm{Re}$ & $\mathrm{SDM}$ \\
\hline $\operatorname{lgc}$ & $-1.329^{* * *}$ & -0.121 & $-0.592^{* * *}$ & $-0.372^{*}$ \\
& $(-11.33)$ & $(-0.55)$ & $(-3.70)$ & $(-1.67)$ \\
hum & $0.072^{* * *}$ & 0.023 & $0.056^{* * *}$ & -0.030 \\
& $(4.39)$ & $(1.05)$ & $(2.84)$ & $(-1.01)$ \\
roa & $0.021^{* * *}$ & $0.046^{* * *}$ & $0.040^{* * *}$ & $0.042^{* * *}$ \\
& $(3.49)$ & $(5.06)$ & $(5.00)$ & $(3.80)$ \\
mar & 0.005 & $0.264^{* *}$ & $0.236^{* *}$ & -0.191 \\
\multirow{2}{*}{ pro } & $(0.04)$ & $(2.23)$ & $(2.10)$ & $(-1.30)$ \\
& $1.464^{* * *}$ & -0.985 & 0.197 & $-2.031^{* *}$ \\
\multirow{2}{*}{ cons } & $(2.74)$ & $(-1.06)$ & $(0.26)$ & $(-2.40)$ \\
\multirow{2}{*}{ W $*$ lgc } & 0.159 & 0.042 & -0.105 & \\
& $(1.02)$ & $(0.28)$ & $(-0.73)$ & \\
& & & & 1.682
\end{tabular}




$$
\begin{array}{cc}
W * \text { hum } & 0.333 \\
W * \text { road } & (1.29) \\
& 0.272^{* * *} \\
W * \text { mar } & (2.84) \\
& -2.748^{* * *} \\
W * \text { pro } & (-2.61) \\
& -0.792 \\
\rho & (-0.14) \\
\delta^{2} & 1.030^{* * *} \\
& (3.74) \\
& 0.005^{* * *}
\end{array}
$$

\begin{tabular}{lcccc}
\hline $\mathrm{N}$ & 300 & 300 & 300 & 300 \\
$\mathrm{R}^{2}$ & 0.6209 & 0.3240 & 0.5434 & 0.0642 \\
\hline
\end{tabular}

The parentheses represent $\mathrm{Z}$ statistics. ${ }^{* * *}$ is significant at $1 \%$; ${ }^{* *}$ is significant at $5 \%$; ${ }^{*}$ is significant at $10 \%$.

\subsection{Mediation effect analysis}

The 2SLS method was applied to test the results of mediating effects (see Table 9). The regression coefficient of $l g c$ value in column (1) is negative significantly at $1 \%$. The coefficient of $l g c$ in column (2) is significantly positive at $10 \%$. In Column 3, the coefficients of $l g c$ and $f m d$ are both negative and significant at $1 \%$. After calculation, the ZMID value is 1.74 , indicating that there is a significant mediation effect of factor market distortion. Therefore, local government competition can suppress GTFP by factor market distortions. Specifically, local government officials participate in the market competition within their jurisdiction through various means to meet the performance appraisal standards of the superior government and obtain the opportunity of political promotion. For example, local governments use administrative power and policy arrangements to tilt factors of production to individual enterprises, resulting in factors distortion such as factor flow obstacle, factor price rigidity, factor price differentiation, and factor price undervaluation. In places where the factor market is highly distorted, local governments tend to provide preferential policies and tax subsidies to support the development of local traditional enterprises for developing the local economy. However, such enterprises are often three high enterprises (high pollution, high energy consumption, and high emission). Although such enterprises can improve economic benefits and promote employment in the short term, they are prone to lead to overcapacity and environmental pollution in the long term, which will seriously restrict the improvement of GTFP.

Table 9 Mediation effect test

\begin{tabular}{cccc}
\hline \multirow{2}{*}{ Variables } & $(1)$ & $(2)$ & $(3)$ \\
\cline { 2 - 4 } & $\mathrm{gtfp}$ & $\mathrm{fmd}$ & $\mathrm{gtfp}$ \\
\hline $\operatorname{lgc} \mathrm{C}$ & $-1.329^{* * *}$ & $0.115^{*}$ & $-1.265^{* * *}$ \\
& $(-9.69)$ & $(1.83)$ & $(-9.33)$ \\
fmd & & & $-0.548^{* * *}$
\end{tabular}




\begin{tabular}{cccc} 
hum & $0.072^{* * *}$ & $-0.077^{* * *}$ & $0.030^{*}$ \\
& $(3.90)$ & $(-7.04)$ & $(1.83)$ \\
roa & $0.021^{* * *}$ & $-0.007^{* *}$ & $0.017^{* *}$ \\
& $(2.63)$ & $(-2.24)$ & $(2.32)$ \\
mar & 0.005 & $-0.285^{* * *}$ & -0.151 \\
& $(0.04)$ & $(-3.99)$ & $(-1.20)$ \\
pro & $1.464^{* * *}$ & $-1.744^{* * *}$ & 0.508 \\
& $(3.28)$ & $(-4.51)$ & $(1.19)$ \\
\multirow{2}{*}{ cons } & 0.159 & $1.568^{* * *}$ & $1.019^{* * *}$ \\
& $(0.94)$ & $(14.27)$ & $(4.85)$ \\
$Z_{\text {mid }}$ & & 1.74 & 300 \\
$\mathrm{~N}$ & 300 & 300 & 0.664 \\
$\mathrm{R}^{2}$ & 0.621 & 0.642 & \\
\hline
\end{tabular}

The parentheses represent $\mathrm{Z}$ statistics. ${ }^{* * *}$ is significant at $1 \%$; ${ }^{*}$ is significant at $5 \%$; ${ }^{*}$ is significant at $10 \%$.

\subsection{Regional heterogeneity analysis}

The natural conditions and the foundation of economic development vary greatly from region to region in China. Comparing provinces at different levels together may obscure the real results among provinces. Therefore, according to the geographical location and economic development level, the statistics are divided into eastern, central, and western regions to further examine the results(see Table 10). $\rho$ value reveals that the spillover effects of GTFP still exist between different regions. Besides, in the eastern and central regions, local government competition has no significant inhibiting effect on green total factor productivity. However, in the western region, local government competition still significantly inhibits GTFP growth at $1 \%$.

On the one hand, in the case of the eastern and central regions, the degree of economic development is relatively high. As the central government puts forward higher environmental target constraints on local governments, local governments have to invest more money in environmental governance, which is conducive to alleviating the pressure caused by economic racing. On the other hand, the local governments have inherent advantages in introducing advanced production technology and high-quality human capital, which is conducive to the research and development and use of clean technology, and then promote the green transformation of the economy. However, although the local governments have begun an economic transformation, under the constraints of the traditional political incentive assessment indicators, the traces and inertia effects of extensive economic development still exist. In general, the inter-governmental competition weakens the damage to the ecological environment, while local government competition influence on GTFP is not significant.

Due to the unique geographical location of the western region, competition for economic growth is still common among local governments. The western region has a lower economic volume and a single source of financial revenue and prefers to pursue GDP growth. As a result of the above behaviors, the local governments in the western region pay less attention to eco-environmental protection, which is not conducive to the promotion of GTFP. Besides, the western region has accepted most of the backward production capacity and eliminated industries from the east and central regions, so as to maintain its competitive advantage in the political promotion. However, 
Those industries that have been transferred are often heavy industries with overcapacity and serious pollution, which have become the main way for local governments to increase GDP growth rate.

Table 10 Regional heterogeneity results

\begin{tabular}{|c|c|c|c|c|}
\hline Varia & ables & Eastern region & Central region & Western region \\
\hline \multirow{2}{*}{\multicolumn{2}{|c|}{$\lg c$}} & -0.365 & -0.664 & $-0.920^{* * *}$ \\
\hline & & $(-0.41)$ & $(-0.69)$ & $(-3.60)$ \\
\hline \multirow{2}{*}{\multicolumn{2}{|c|}{ hum }} & -0.085 & -0.011 & -0.020 \\
\hline & & $(-1.03)$ & $(-0.22)$ & $(-0.49)$ \\
\hline \multirow{2}{*}{\multicolumn{2}{|c|}{ road }} & $0.049^{* *}$ & $0.130^{* * * *}$ & $0.045^{* * *}$ \\
\hline & & $(2.02)$ & $(3.14)$ & $(3.04)$ \\
\hline \multirow{2}{*}{\multicolumn{2}{|c|}{ mar }} & -0.440 & $-0.789^{* *}$ & 0.171 \\
\hline & & $(-1.29)$ & $(-2.10)$ & $(0.80)$ \\
\hline \multirow{2}{*}{\multicolumn{2}{|c|}{ pro }} & $-2.730^{*}$ & $16.183^{* * *}$ & -0.733 \\
\hline & & $(-1.74)$ & $(3.60)$ & $(-0.51)$ \\
\hline & $* g o v$ & -1.860 & 90.639 & -2.064 \\
\hline & & $(-0.51)$ & $(0.32)$ & $(-1.51)$ \\
\hline \multirow{2}{*}{\multicolumn{2}{|c|}{$W * h u m$}} & 0.175 & $-26.801^{*}$ & 0.018 \\
\hline & & $(0.55)$ & $(-1.76)$ & $(0.09)$ \\
\hline \multirow[t]{2}{*}{$W$} & * road & -0.004 & $47.112^{* * *}$ & 0.093 \\
\hline & & $(-0.05)$ & $(3.52)$ & $(0.96)$ \\
\hline \multirow[t]{2}{*}{$W$} & $*$ mar & $-2.490^{* * *}$ & $-386.811^{* * *}$ & 0.872 \\
\hline & & $(-2.82)$ & $(-2.82)$ & $(0.96)$ \\
\hline \multirow[t]{6}{*}{$W$} & * pro & -0.005 & $5826.648^{* * *}$ & -2.403 \\
\hline & & $(-0.00)$ & $(3.44)$ & $(-0.29)$ \\
\hline & $\rho$ & $0.480^{* *}$ & $0.255^{* * * *}$ & $0.517^{*}$ \\
\hline & & $(2.32)$ & $(3.56)$ & $(1.90)$ \\
\hline & $\delta^{2}$ & $0.006^{* * * *}$ & $0.003^{* * * *}$ & $0.003^{* * *}$ \\
\hline & & (7.13) & $(5.79)$ & $(7.24)$ \\
\hline \multicolumn{2}{|l|}{$\mathrm{N}$} & 110 & 80 & 110 \\
\hline \multicolumn{2}{|l|}{$\mathrm{R}^{2}$} & 0.0392 & 0.3110 & 0.3625 \\
\hline
\end{tabular}
significant at $10 \%$.

\subsection{Regional heterogeneity analysis of mediation effect results}

Simultaneously, the 2SLS is used to test the regional heterogeneity of mediation effects (see Table 10). For the eastern and central regions, columns (1), (2), (4), and (5) indicate that local government competition has negative effects on GTFP and factor market distortion, but not significant. In columns (2) and (5) reveal that the mediation impact of factor market distortion as a mediation variable on local government competition and GTFP does not significant. The coefficient of $l g c$ in column (7) is significantly negative at a 5\% confidence level. The result reveals that local government competition suppresses the improvement of regional GTFP in the western region. The coefficient of $l g c$ in column (8) implies that local government competition can reinforce factor market distortion in the western region. The coefficient of $f m d$ in column (9) is significantly negative at $5 \%$ level, and the coefficient of $\operatorname{lgc}$ is negative but not significant. Based on the 
calculation, the $Z_{\text {mid }}$ value is 1.95 , so the mediation effect is significant at $10 \%$. Local government competition can inhibit GTFP through factor market distortions.

On the one hand, for the eastern and central regions, with the concept of "new development concept" and " lucid waters and lush mountains are invaluable assets ", the official promotion model is no longer based on the absolute GDP growth rate as the assessment indicator. The competition among officials in this region includes more aspects such as environmental governance and the supply of public goods, which gradually changes from "bottom-to-bottom competition" to "top-totop competition". On the other hand, the eastern and central regions usually have a more open trading market, a good factor market order, and a complete property rights trading system, which can reduce the inhibitory effect on GTFP.

However, in the western region, local governments tend to adopt a 'yardstick competition' approach to economic growth, which is still driven by quantity rather than quality. For example, in the western region, government officials will relax their regulation of the environment because of their own political promotion. Through the introduction of industrial enterprises with high pollution, high energy consumption, and high emissions to achieve rapid economic growth, in order to gain an advantage in the competition with neighboring provinces and obtain promotion capital from performance appraisal. The above government actions do not optimize the allocation of elements in various industrial sectors, which leads to factor market distortion. Meanwhile, The above government actions also cause an imbalance in the allocation of resources, human capital, and other factors, which is ultimately detrimental to the improvement of GTFP. Additionally, factor distortion indirectly weakens the spatial flow of labor and technology factors forming technical barriers and information gaps. It not only hinders the dynamic change of green technology research and development, but also makes the development of the western region difficult to get rid of the dilemma of pollution haven and factor curse, and finally significantly reduces the GTFP.

Table10 The result of the mediation effect of regional heterogeneity

\begin{tabular}{|c|c|c|c|c|c|c|c|c|c|}
\hline \multirow[t]{2}{*}{ Variables } & \multicolumn{3}{|c|}{ Eastern region } & \multicolumn{3}{|c|}{ Central region } & \multicolumn{3}{|c|}{ Western region } \\
\hline & (1) & (2) & (3) & (4) & (5) & (6) & (7) & (8) & (9) \\
\hline & $g t f p$ & fmd & $g t f p$ & $g t f p$ & fmd & $g t f p$ & $g t f p$ & fmd & $g t f p$ \\
\hline \multirow[t]{2}{*}{$\lg c$} & -0.482 & -0.291 & -0.649 & -0.418 & -0.096 & -0.375 & $-0.502^{* *}$ & $0.452^{* * *}$ & -0.271 \\
\hline & $(-0.78)$ & $(-0.80)$ & $(-1.11)$ & $(-0.62)$ & $(-0.30)$ & $(-0.52)$ & $(-2.10)$ & (2.99) & $(-1.10)$ \\
\hline \multirow[t]{2}{*}{ fmd } & & & -0.327 & & & $-0.187^{* *}$ & & & $-0.334^{* *}$ \\
\hline & & & $(-1.63)$ & & & $(-2.19)$ & & & $(-2.57)$ \\
\hline \multirow[t]{2}{*}{ hum } & 0.051 & $-0.104^{* * *}$ & 0.034 & 0.026 & -0.028 & 0.023 & $0.065^{*}$ & -0.039 & $0.049^{*}$ \\
\hline & $(1.33)$ & $(-2.94)$ & $(0.82)$ & $(0.51)$ & $(-1.30)$ & $(0.49)$ & $(1.72)$ & $(-1.16)$ & $(1.65)$ \\
\hline \multirow[t]{2}{*}{ roa } & $0.036^{*}$ & $-0.027^{* * *}$ & 0.022 & $0.038^{*}$ & -0.013 & 0.035 & 0.040 & $-0.039^{* *}$ & 0.020 \\
\hline & $(1.81)$ & $(-3.13)$ & $(1.10)$ & $(1.75)$ & $(-0.73)$ & (1.59) & (1.39) & $(-2.36)$ & $(0.66)$ \\
\hline \multirow[t]{2}{*}{ mar } & 0.465 & $-0.717^{* * *}$ & 0.216 & 0.139 & -0.307 & 0.072 & 0.047 & 0.022 & 0.140 \\
\hline & $(1.20)$ & $(-3.77)$ & $(0.54)$ & $(0.65)$ & $(-1.49)$ & $(0.34)$ & $(0.38)$ & $(0.08)$ & (1.63) \\
\hline \multirow[t]{2}{*}{ pro } & -0.370 & $-1.092^{*}$ & -1.202 & 1.726 & $-13.611^{* * *}$ & -1.020 & 0.803 & $-6.874^{* * *}$ & $-1.380^{* *}$ \\
\hline & $(-0.38)$ & $(-1.72)$ & $(-1.64)$ & $(0.92)$ & $(-5.64)$ & $(-0.47)$ & $(0.62)$ & $(-2.71)$ & $(-2.20)$ \\
\hline \multirow[t]{2}{*}{ _cons } & -0.169 & $2.345^{* * *}$ & 0.499 & 0.158 & $1.298^{* * *}$ & 0.383 & -0.119 & $1.094^{* * *}$ & 0.220 \\
\hline & $(-0.57)$ & (11.33) & $(0.84)$ & $(0.41)$ & $(7.00)$ & (1.08) & $(-0.48)$ & $(3.41)$ & $(1.01)$ \\
\hline$Z_{\text {mid }}$ & & 0.72 & & & 0.30 & & & 1.95 & \\
\hline $\mathrm{N}$ & 110 & 110 & 110 & 80 & 80 & 80 & 110 & 110 & 110 \\
\hline
\end{tabular}




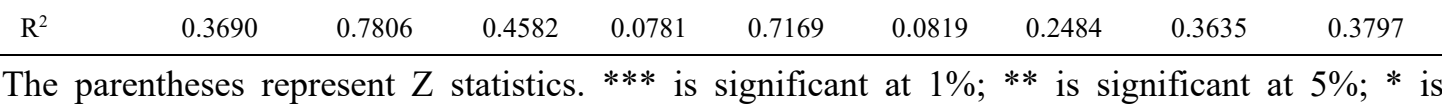
significant at $10 \%$.

\section{Conclusions and policy implications}

Improper competition among local governments is an important factor restricting the green growth of the Chinese regional economy. At the same time, the specific assessment of the impact of factor market distortion on GTFP is of crucial significance for China to achieve high-quality economic development. Therefore, a topic of concern is the relationship among factor market distortions, local government competition, and green total factor productivity. We examine local government competition influence on GTFP from the perspective of factor market distortion using 2008-2017 Chinese provinces statistical data. Furthermore, we examine the mediation effect of factor market distortions. Statistical empirical results found that the spatial correlation of GTFP is significantly present across Chinese different provinces. The growth of GTFP will be significantly inhibited by local government competition. Moreover, local government competition can indirectly inhibit the improvement of GTFP by factor market distortion. $Z$ mid value is 1.74 , indicating that there is a significant mediation effect of factor market distortion. Regional heterogeneity results indicate that in the eastern and central regions GTFP has not been significantly inhibited by local government competition. Moreover, local government competition did not inhibit the growth of GTFP by distorting factor markets. In the western region, local government competition not only inhibited the growth of GTFP, but also inhibited the growth of GTFP by distorting the factor market.

In order to guide restrain local government behavior and reduce factor market distortion, some feasible policy implications in this article are as follows

First, policymakers should scientifically guide local government behavior and constantly regulate local government competition. Thus, the supply of public goods with a strong externality of the ecological environment can be optimized. The political promotion system based on environmental governance and economic growth should be constructed, and the incentive design of the civil servant selection system should be improved, to guide local governments to compete in an orderly and reasonable manner. Policymakers should also get rid of the factor market distortions and local protectionism brought about by the "vassal economy" for the free flow and effective allocation of factors of production.

Second, policymakers should strengthen the market-oriented reform of factor resources and improve the price formation mechanism of factor resources. On the one hand, policymakers should reduce administrative procedures, enact regulations to ease market access, the crackdown on monopolistic practices, and allow the free flow of factors of production among different sectors. On the other hand, policymakers should reform the prices of resource products and promote the marketization of resource prices. The market demand and the scarcity of resources can be reflected by the real price. The price formation mechanism should be constantly reformed and the role of market and price mechanism in resource allocation should be brought into full play.

Finally, policymakers should strengthen support for enterprises' technological innovation through fiscal and tax measures and encourage enterprises to develop green technologies. Then, through green technology innovation, the economic system of green, low-carbon, and circular development is constructed for realizing the growth of GTFP. The economic development between different regions of China is extremely uneven. In the process of green transformation, policymakers 
need to implement differentiated performance assessment systems and green development policies according to local conditions. Similarly, the integration of factor markets across regions should be vigorously pursued. Policymakers should also promote a market environment of fair competition and the rule of law, and establish a market regulatory system that encourages innovation and prudence.

\section{Declarations}

\section{Funding:}

This research received no external funding.

\section{Competing Interests:}

The authors declare that they have no known competing financial interests or personal relationships that could have appeared to influence the work reported in this paper.

\section{Ethics approval and consent to participate:}

Not applicable.

\section{Consent to Publish:}

Not applicable.

\section{Authors Contributions:}

Juan Tang: Conceptualization, Project administration, Formal analysis, Writing - review \& editing, Data curation, Writing - original draft. Abdul Rahim Bin Abdul Samad: Software, Visualization, Writing - original draft, Writing - review \& editing, Formal analysis. Fangming Qin: Writing - review \& editing, Writing - original draft, Conceptualization, Methodology, Funding acquisition, Supervision.

\section{Availability of data and materials:}

Not applicable.

\section{References}

Baron, R. M., \& Kenny, D. A. (1986). The moderator-mediator variable distinction in social psychological research: Conceptual, strategic, and statistical considerations. Journal of Personality and Social Psychology, 51(6), 1173-1182.

Baskaran, T., \& Feld, L. P. (2013). Fiscal Decentralization and Economic Growth in OECD Countries: Is There a Relationship? Public Finance Review, 41(4), 421-445.

Boyne, G. A. (1996). Competition and local government: A public choice perspective. Urban Studies, 33(4-5), 703-721.

Canavire-Bacarreza, G., Martinez-Vazquez, J., \& Yedgenov, B. (2019). Identifying and disentangling the impact of fiscal decentralization on economic growth. World Development, 127, 104742 .

Chaudhuri, S. (2005). Labour Market Distortion, Technology Transfer and Gainful Effects of Foreign Capital. The Manchester School, 73(2), 214-227.

Chen, J., Huang, J., Huang, X., Sun, S., Hao, Y., \& Wu, H. (2020). How does new environmental law affect public environmental protection activities in China? Evidence from 
structural equation model analysis on legal cognition. Science of The Total Environment, 714, 136558 .

Chen, Y., Liu, B., Shen, Y., \& Wang, X. (2016). The energy efficiency of China's regional construction industry based on the three-stage DEA model and the DEA-DA model. Ksce Journal of Civil Engineering, 20(1), 34-47.

Deng Xiaolan, Liu Ruohong \& Xu Yanjun.(2019). The impact of "competition for growth" and "competition for harmony" on the scale of local government debt: A mediating mechanism based on investment impulse. Comparison of Economic and Social Systems (04),55-67.

Deng, Z., Jiang, N., Song, S., \& Pang, R. (2021). Misallocation and price distortions: A revenue decomposition of medical service providers in China. China Economic Review, 65, 101574.

Dierkes, M., Germer, S., \& Sejdiu, V. (2020). Probability Distortion, Asset Prices, and Economic Growth. Journal of Socio-Economics, 84, 101476.

Edmiston, K., \& Turnbull, G. K. (2003). Local government competition for economic development. Andrew Young School of Policy Studies at Georgia State University: Working paper, (03-07).

Fried, H. O., Lovell, C. K., Schmidt, S. S., \& Yaisawarng, S. (2002). Accounting for environmental effects and statistical noise in data envelopment analysis. Journal of productivity Analysis, 17(1-2), 157-174.

Fuentes, R., Fuster, B., \& Lillo-Bañuls, A. (2016). A three-stage DEA model to evaluate learning-teaching technical efficiency. Expert Systems With Applications, 48, 89-99.

Gao Peiyong. (2019). Grasp the proactive fiscal policy based on high-quality development and understand the profound changes in the allocation pattern. Financial sector (16), 39-15.

Hao, Y., Gai, Z., \& Wu, H. (2020). How do resource misallocation and government corruption affect green total factor energy efficiency? Evidence from China. Energy Policy, 143, 111562.

Hao, Y., Zheng, S., Zhao, M., Wu, H., Guo, Y., \& Li, Y. (2020). Reexamining the relationships among urbanization, industrial structure, and environmental pollution in China-New evidence using the dynamic threshold panel model. Energy Reports, 6, 28-39.

Haufler, A., \& Maier, U. (2019). Regulatory competition in capital standards: a 'race to the top'result. Journal of Banking \& Finance, 106, 180-194.

Hawkins, C. V. (2010). Competition and cooperation: Local government joint ventures for economic development. Journal of urban affairs, 32(2), 253-275.

Hong, Y., Lyu, X., Chen, Y., \& Li, W. (2020). Industrial agglomeration externalities, local governments' competition and environmental pollution: Evidence from Chinese prefecture-level cities. Journal of Cleaner Production, 277, 123455.

Hsieh, C.-T., \& Klenow, P. J. (2009). Misallocation and Manufacturing TFP in China and India. Quarterly Journal of Economics, 124(4), 1403-1448.

Huang, Y., \& Tao, K. (2010). Factor Market Distortion and the Current Account Surplus in China. Asian Economic Papers, 9(3), 1-36.

Iacobucci, D. (2012). Mediation analysis and categorical variables: The final frontier. Journal of Consumer Psychology, 22(4), 582-594.

Jondrow, J., Lovell, C. K., Materov, I. S., \& Schmidt, P. (1982). On the estimation of technical inefficiency in the stochastic frontier production function model. Journal of econometrics, 19(2-3), 233-238.

Kivyiro, P., \& Arminen, H. (2014). Carbon dioxide emissions, energy consumption, economic 
growth, and foreign direct investment: Causality analysis for Sub-Saharan Africa. Energy, 74, 595606.

Kuai, P., Yang, S., Tao, A., \& Khan, Z. D. (2019). Environmental effects of Chinese-style fiscal decentralization and the sustainability implications. Journal of Cleaner Production, 239, 118089.

Kui-za, D. (2015). The effect and enterprise diffence of factor market distortion on R\&D input:An empirical analysis of China's high-tech industries. Studies in Science of Science.

Lesage, J. P. (2009). Introduction to spatial econometrics.

Levinson, A. (2003). Environmental regulatory competition: A status report and some new evidence. National Tax Journal, 91-106.

Li, H., Zhang, M., Li, C., \& Li, M. (2019). Study on the spatial correlation structure and synergistic governance development of the haze emission in China. Environmental Science and Pollution Research, 26(12), 12136-12149.

Li, K., \& Lin, B. (2016). Impact of energy conservation policies on the green productivity in China's manufacturing sector: Evidence from a three-stage DEA model. Applied Energy, 168, 351363.

Lin, B., \& Chen, Z. (2018). Does factor market distortion inhibit the green total factor productivity in China?. Journal of Cleaner Production, 197, 25-33.

Lin, J. Y., \& Liu, Z. (2000). Fiscal decentralization and economic growth in China. Economic development and cultural change, 49(1), 1-21.

Liu, F., \& Qiu, S. B. (2020). Relations between factor-market distortion and environmental pollution - analysis of intermediate effect based on technological innovation. Desalination and Water Treatment, 188, 303-308.

Liu, L., Ding, D., \& He, J. (2019). Fiscal Decentralization, Economic Growth, and Haze Pollution Decoupling Effects: A Simple Model and Evidence from China. Computational Economics, 54(4), 1423-1441.

Markusen, J. R., Morey, E. R., \& Olewiler, N. (1995). Competition in regional environmental policies when plant locations are endogenous. Journal of Public economics, 56(1), 55-77.

Oates, W. E. (1993). Fiscal decentralization and economic development. National tax journal, 46(2), 237-243.

Oates, W. E., \& Schwab, R. M. (1988). Economic competition among jurisdictions: efficiency enhancing or distortion inducing?. Journal of public economics, 35(3), 333-354.

Ogawa H, Wildasin DE (2009) Think locally, act locally: spillovers, spillbacks, and efficient decentralized policy making. Am Econ Rev 99:1206-1217.

Ouyang, X., Zhuang, W., \& Sun, C. (2019). Haze, health, and income: An integrated model for willingness to pay for haze mitigation in Shanghai, China. Energy Economics, 84, 104535.

Pan, X., Li, M., Guo, S., \& Pu, C. (2020). Research on the competitive effect of local government's environmental expenditure in China. Science of The Total Environment, 718, 137238.

Porter, G. (1999). Trade Competition and Pollution Standards: "Race to the Bottom" or "Stuck at the Bottom": The Journal of Environment \& Development, 8(2), 133-151.

Revelli, F., \& Tovmo, P. (2007). Revealed yardstick competition: Local government efficiency patterns in Norway. Journal of Urban Economics, 62(1), 121-134.

Shi, X., \& Sun, S. (2017). Energy price, regulatory price distortion and economic growth: a case study of China. Energy Economics, 63, 261-271.

Shi, X., Yu, J., \& Cheong, T. S. (2020). Convergence and distribution dynamics of energy 
consumption among China's households. Energy Policy, 142, 111496.

Song, K., Bian, Y., Zhu, C., \& Nan, Y. (2020). Impacts of dual decentralization on green total factor productivity: evidence from China's economic transition. Environmental Science and Pollution Research, 27(12), 14070-14084.

Song, M., Du, J., \& Tan, K. H. (2018). Impact of fiscal decentralization on green total factor productivity. International Journal of Production Economics, 205, 359-367.

Sun, C., Zhan, Y., \& Du, G. (2020). Can value-added tax incentives of new energy industry increase firm's profitability? Evidence from financial data of China's listed companies. Energy Economics, 86, 104654.

Sun, H., Edziah, B. K., Sun, C., \& Kporsu, A. K. (2019). Institutional quality, green innovation and energy efficiency. Energy policy, 135, 111002.

Wu, H., Gai, Z., Guo, Y., Li, Y., Hao, Y., \& Lu, Z.-N. (2020). Does environmental pollution inhibit urbanization in China? A new perspective through residents' medical and health costs. Environmental Research, 182, 109128.

Wu, H., Hao, Y., \& Ren, S. (2020). How do environmental regulation and environmental decentralization affect green total factor energy efficiency: Evidence from China. Energy Economics, 91, 104880.

Wu, H., Ren, S., Yan, G., \& Hao, Y. (2020). Does China's outward direct investment improve green total factor productivity in the "Belt and Road" countries? Evidence from dynamic threshold panel model analysis. Journal of Environmental Management, 275, 111295.

Yang, M., Yang, F., \& Sun, C. (2018). Factor market distortion correction, resource reallocation and potential productivity gains: An empirical study on China's heavy industry sector. Energy Economics, 69, 270-279.

Yang, T., Liao, H., \& Wei, Y. M. (2020). Local government competition on setting emission reduction goals. Science of The Total Environment, 745, 141002.

Yang, X., Zhang, J., Ren, S., \& Ran, Q. (2020). Can the New Energy Demonstration City policy reduce environmental pollution? Evidence from a quasi-natural experiment in China. Journal of Cleaner Production, 125015.

Yang, Z., Shao, S., Fan, M., \& Yang, L. (2021). Wage distortion and green technological progress: A directed technological progress perspective. Ecological Economics, 181, 106912.

Zhang, J., Wang, J., Yang, X., Ren, S., Ran, Q., \& Hao, Y. (2020). Does local government competition aggravate haze pollution? A new perspective of factor market distortion. SocioEconomic Planning Sciences, 100959.

Zhao, X., Liu, C., Sun, C., \& Yang, M. (2020). Does stringent environmental regulation lead to a carbon haven effect? Evidence from carbon-intensive industries in China. Energy Economics, $86,104631$.

Zhou Lian. (2007). A study on the promotion tournament model of local officials in China. Economic Research (07), 36-50. 